\title{
Registration-analytical security of growing biopower crops
}

\section{Perepelytsia $\mathbf{N}$.}

phd. econ. science

\section{National Scientific Center "Institute for Agriculture Engineering and Electrification" NAAS of Ukraine}

The purpose. To develop methodical approaches to practical recommendations concerning improvement of registration-analytical security of growing biopower crops. Methods. Monographic, analysis and synthesis, abstract-logical, table. Results. Problem questions are considered of registration-analytical security of control over growing biopower crops, and their classification is realized as plants of accounting and monitoring. According to classification attributes the order of formation of registration policy regarding expenditures of production on growing biopower crops, in particular amortization costs for long-term biological assets is offered. Conclusions. Approaches concerning the count of perennial biopower plantings which application will ensure formation of sinking fund as the source. Bibliogr.: 12 titles.

Key words: biopower crops, long-term biological assets, amortization, technical-technological security, nomenclature of items of estimation.

Problem statement. Modern energy dependence of Ukraine has become a catalyst for the development of domestic renewable energy, one of the promising directions of which was the new branch of agroindustrial complex - bioenergy. Currently, the main priorities of this industry are the search for cheap energy bioremediation, effective technical and technological solutions, the creation of the necessary infrastructure for the cultivation of bioenergy crops and the processing of biomass.

There is a wide range of opinions in the scientific literature regarding the effectiveness of cultivating bioenergetic crops for the purpose of processing biofuels. Most researchers report high profitability of this kind of activity, but in the economic sciences the clear methodology of accounting, cost estimation and determination of economic efficiency of cultivating bioenergetic crops has not yet been developed, which does not allow to objectively evaluate the effectiveness of the use of technical and technological support, to investigate the impact of the development of bioenergy industry on agricultural production in general.

Analysis of recent research and publications. An analysis of recent research has shown that in a series of works, researchers partly highlight the efficiency of biofuel production, focusing on technical and technological aspects of bioenergy crops [1-4], or consider the problem of assessing the potential for the development of this type of renewable energy at national or regional levels [5-6]. However, certain attempts to study some of the economic aspects of energy crops can still be found in publications [7-9]. However, the approaches proposed in these works mainly concern only one-year energy crops and their processing into liquid biofuels, so they do not solve the mentioned problem in general, and in particular, concerning multiyear bioenergetic cultures, which testifies to the relevance of the chosen research direction.

Purpose. The purpose of our scientific work is to develop methodological approaches to practical recommendations for improving the accounting and analytical support for the cultivation of bioenergy crops for the adoption of sound management decisions in order to effectively use the technical and technological basis of production and sustainable development of the industry.

Methods - monographic, analysis and synthesis, abstract-logical, tabular.

Presentation of the main material. In recent years, due to rising prices for fossil fuels and energy resources significantly increased interest in the use of alternative energy sources. One of their varieties is solid biofuels, which are produced from biomass of fast-growing energy crops.

The processes of economic integration of Ukraine into the European Union and the world community, as well as market transformations in the country, place new demands on the quality of accounting and analytical information for the management of the development of the bioenergy industry and the evaluation of the efficiency of cultivating bioenergy crops in agricultural enterprises. As in most cases, agrarian enterprises need to attract foreign capital to invest in a plantation of energy crops and technical and technological support, their managers need reliable and complete analytical information on the results of production and financial activities in this direction. 
Until recently in the scientific literature on cost accounting, analysis and determination of the cost of growing bioenergy crops remained theoretically and methodologically not disclosed because the same technology of cultivation had widespread use in Ukraine.

Let's consider in more detail the biomass of energy crops as an object of accounting and control, that is, as an agricultural biological asset.

Bioenergy crops grown by agricultural producers for the direct use as fuel or further processing of biofuels belong to the biological assets of the enterprise, since according to $P(C) B O 30$, the biological asset is an animal or plant that, in the process of biological transformation, is capable of producing agricultural products and / or additional biological assets, as well as other economic benefits. The accounting and reporting of such enterprises must meet the requirements of $\mathrm{P}(\mathrm{C}) \mathrm{BO} 30$ "Biological Assets" [10], which is similar to IAS 41 "Agriculture".

To manage the efficiency of bioenergetic crop cultivation, information on the state of biological assets, their transformation, conditions of formation, peculiarities of use, estimation, etc. are required. The biological heterogeneity of bioenergetic cultures necessitates a proper classification of biological assets. The economic factor in the classification is the diverse participation of these biological assets in economic turnover (Fig. 1). Biological assets are divided into long-term ones, which are reflected in non-current assets, and current ones are in current assets.

$\mathrm{P}$ (C) BO 30 involves the allocation of productive perennial plantations into a separate accounting object long-term biological assets.

Technological peculiarities of cultivating bioenergetics require a certain organization of accounting for the costs of their production. In agriculture, the determination of costs is regulated by the relevant regulatory and legal acts on accounting, in particular, P (C) BO 16 "Costs", P (C) BO 30 "Biological Assets", Methodological Recommendations for the Accounting of Biological Assets, approved by the Order of the MFU (№1315 December 29, 2006), as well as Methodical recommendations on planning, accounting and calculation of the cost of production (works, services) of agricultural enterprises № 132 of 18.05.2001.

Figure 1. Classification of bioenergetic crops as an agricultural biological asset

The growth of multi-year bioenergy crops is characterized by high capital intensity, therefore a depreciation fund should be a reliable and significant source of own investments in creation (reproduction) of plantings and updating of the technical base. However, the feature of the new accounting for $\mathrm{P}$ (C) BO 30 is that depreciation is charged only on mature long-term biological assets, the fair value of which can not be determined, ie, long-term biological assets are valued at their original cost.

If long-term biological assets are valued at fair value, there will be no amount of depreciation deductions for bioenergiculture in the composition of production costs. This is due to the fact that in the aging of a longterm biological asset, it changes its market value to the side of reduction, and the resulting difference, according to the current procedure, is subject to the write-off for expenses from the change in the value of the relevant assets, which belongs to the group of other costs of operating activities of the agricultural enterprise. Under this approach, actual production costs and production costs of bioenergy crops will be underestimated, while non-production costs are overestimated. It should be noted that at the end of the period of industrial use of power planes in parallel with the reduction of their returns, which will affect the reduction of economic efficiency, it may be necessary to write off significantly larger amounts of revaluation costs. Thus, the real economic result will be distorted.

The issue of accounting for planting liquidation due to the expiry of their term of industrial use remains unresolved. For example, gardening practices show that the costs of turning trees and cultivating soil are substantial and amount to one third of the cost of gardening the same area [11]. In the domestic Accounts plan, use the special sub-account "Write-off of non-current assets" as part of other expenses. In accordance with the Instruction on the application of the Accountancy Account for assets, capital and liabilities of enterprises and organizations of Ukraine, such expenses are related to expenses of the period and are subject to write-downs on financial results. 
Since all this can automatically affect the amount of net profit or loss in general, most of the outdated plantations may remain uncultivated. To avoid this, it would be expedient to simultaneously, with the addition of new plantings of bioenergy crops, to increase their initial cost to the amount of the planned cost of eliminating long-term energy plantations. Thus, in the course of wearing out of long-term biological assets, depreciation deductions will be accumulated in amount that will ensure their full reproduction.

Given these shortcomings and taking into account the lack of information on the fair value of long-term bioenergy crop plantations in Ukraine due to the lack of a relevant market, such biological assets should be valued at their original cost. Immature long-term biological assets up to the productive age can be estimated by the amount of costs incurred for their establishment and cultivation.

In accordance with the Methodological recommendations on accounting, financial and legal support for laying, care and decommissioning of perennial plantations, the plantations are transferred to productive units and put into operation, provided that the value of the products obtained from young plantings exceeds the current expenses for their cultivation. For many years of bioenergy crops, these terms may be as follows: wood (willow, poplar) - 2-3 years, herbaceous - 1-2 years.

Depreciation is carried out during the useful life of a long-term biological asset, which is established by the enterprise independently upon recognition of its asset (when included on the balance sheet), considering that plantations of energy crops can stably give an increase in biomass within 15-25 years.

In conditions of inflation, depreciation as a source of reproduction of fixed assets in the application of the linear method cannot perform the function assigned to it, as enterprises are not able to accumulate depreciation deductions in an amount sufficient for the implementation of new investment projects [12]. Therefore, in the active part of fixed assets, the most expedient way is to calculate the depreciation of the diminishing balance (regressive) and the sum of numbers of years of useful life (cumulative), which enable to accumulate amortization deductions in shorter times, keeping them from inflation depreciation. In order to dispose of fixed assets as soon as possible, it is recommended to apply a method of accelerated reduction of residual value.

When using the method of accelerated depreciation liquidation value of the object is not included. The annual amount of depreciation is defined as the product of the residual value of the object at the beginning of the accounting year or the initial value at the date of commencement of depreciation and the annual depreciation rate, which is calculated based on the useful life of the object, and doubles. The application of this method makes it possible for the first half of the useful life of the use of fixed assets to be repaid to $60-70 \%$ of their value.

At the current level of production, more than $40 \%$ of all plant production costs are machine and tractor park, therefore, for its more efficient use it is necessary to carry out constant control over the costs of maintenance and operation of the ICC, especially if there are no standards for the use of analog machines, which is typical for the specialized techniques for cultivating bioenergetic crops.

In order to optimize the problem, operating costs for the mechanization of production of bioenergy crops must be divided into constant and variables. To constant costs should include interest on investment costs, storage costs of the machine, insurance costs and depreciation. Variable costs include the remuneration of the maintenance staff (operator, machine operator), the cost of fuel and lubricants (CFL), the cost of repairs and maintenance $(\mathrm{M})$, as well as the cost of auxiliary technological (consumable) materials.

For households involved in the cultivation of bioenergy crops, we offer the following nomenclature of costing items of expenditure (Table 1).

Table 1. Nomenclature of articles on the costs of cultivating bioenergy crops

Typical nomenclature Detailed nomenclature

Labor costs - pay for the main and additional employees involved in the cultivation of bioenergy crops;

Deductions for social measures - deductions for social measures for the main and additional employees;

Fertilizers - mineral fertilizers;

- organic fertilizers;

- microbiological fertilizers.

Plant protection products - pesticides;

- biological products.

Seeds and seedlings are seeds

- cuttings 
- rhizomes.

Works and services - works and services of auxiliary productions;

- Work and services of third-party organizations.

Depreciation deduction - depreciation of bioenergy plantations in service (at initial recognition).

Maintenance of ICC - constant maintenance costs for maintenance and use of machine-tractor park

- Variable maintenance costs for the maintenance and use of the machine tractor park

Other direct expenses - rent for land plots;

- taxes and fees;

- planting insurance;

- the cost of low value materials and other costs.

Total production costs - Total production costs for bioenergetics plantations

The seasonal nature of the production of bioenergy raw materials results in the fact that the time of the incurred costs does not coincide with the time of receipt of proceeds from the sale of products, it can occur during different reporting periods (fiscal years). Therefore, enterprise executives need objective information that can be obtained through planning activities, expeditiously identifying costs, developing detailed technological maps for growing crops and obtaining products that will increase the efficiency of managing these enterprises.

\section{Conclusions}

The construction of accounting and management information in the field of bioenergetics crops must meet the requirements of the technological process and the peculiarities of the industry. The approaches to accounting for multi-year bioenergetics plantations as long-term biological assets of use of which will provide the formation of a depreciation fund as a source of own investment resources for the continuous updating of power plants and their technical and technological support.

\section{Biblography}

1. Energy willow: technology of cultivation and use. Under the command ed. V.M. Sinchenko. Vinnitsa: LLC "Nilan LTD", 2015. 340 p.

2. Mikitin T.M. (2015). Efficiency of growing energy crops in Polissya. Bulletin of the Dnipropetrovsk State Agrarian and Economic University. № 1 (35). P. 102-105.

3. Kalinichenko O. V., Plotnik O.D. (2011). Economic efficiency of production of the culture of the mythgrasse in Ukraine. Scientific works of the Poltava State Agrarian Academy . T. 1., Pub. 2. Economics. Poltava: PDAA. P. 136-141.

4. Gumetnik M.Ya. Kuril V. L., Gomentik M. Ya. [and others]. (2011). Efficiency of Growing HighProductive Energy Cultures. Visnyk of Lviv National Agrarian University. 2011. № 15 (2). P.85-90.

5. Mikitin T.M. (2015). Features of bioenergy development at the regional level. Economic forum. №3. P. 221-227.

6. Boyarchuk M.V. Multicriteria assessment of the efficiency of production of energy crops on the willow example. Entrepreneurship in the field of agroindustrial complex P. 55-63.

7. Fedukha M. (2016). Biological fuel as an object of accounting and control. Development of agrarian business in the conditions of globalization: materials International. science-practice conf. with the participation of foreigners. Stud. Ternopil: Aston. pp. 190-193.

8. Bondar V.C., Fursa A.V. (2015). Economic substantiation of technologies of cultivation and processing of plant bio-raw materials for solid fuels. Economics of AIC. No. 3. pp. 22-27.

9. Krasuska E. Rosenqvist H. (2012). Eronomics of energy crops in Poland today and in the future. Biomass Bioenergy. Vol. 38. pp.23-33.

10. Regulation (standard) of accounting №30 "Biological Assets", approved by the order of the Ministry of Finance of Ukraine dated November 18, 2005, № 790.

11. Dokashvili M.B. (2014). Accounting for long-term biological plant production assets. Development Management. № 2 (165). pp. 53-56.

12. Kostyuk L. A. (2009). The system of depreciation of basic means of production in horticulture. Economy of agroindustrial complex. № 4. pp. 24-28. 